\title{
Acute Mono-appendicitis in a Case of Duplex Appendix: A Rare Finding
}

\author{
Ahmet Akbaş ${ }^{1}$, Nadir Adnan Hacim ${ }^{1}$, Fatih Daşiran², Hasan Dagmura² and Emin Daldal ${ }^{2}$ \\ ${ }^{1}$ Department of General Surgery and Surgical Oncology, Bagcilar Training and Research Hospital, Istanbul, Turkey \\ ${ }^{2}$ Department of General Surgery, Gaziosmanpaşa University, Tokat, Turkey
}

\begin{abstract}
Appendiceal duplication is an extremely rare entity in adulthood. It is usually diagnosed incidentally during laparotomy performed for another indication. Herein, we present a case of double appendicitis in a 31-year male who underwent laparotomy with a preliminary diagnosis of acute appendicitis. Two appendices attached via separate bases to a cecum were identified intraoperatively. One of them was thick-walled, partial 1 perforated from the apex region and the other one was normal looking. Both had their own radices. They were stuck together at their apical parts. Appendicectomy was performed for both of them. Due to the fact that appendicectomy is the most common abdominal surgery procedure, surgeons should always bear in mind this rare anomaly, in order to prevent complications.
\end{abstract}

Key Words: Appendiceal duplication, Cecum, Anatomic variation.

How to cite this article: Akbaş A, Hacim NA, Daşiran F, Dagmura H, Daldal E. Acute Mono-appendicitis in a Case of Duplex Appendix: A Rare Finding. J Coll Physicians Surg Pak 2020; 30(04):440-442. DOI: https://doi.org/10.29271/jcpsp.2020.04.440.

\section{INTRODUCTION}

The most common surgical procedure for intraabdominal surgery is appendicectomy. The overall risk of appendicitis is approximately $7.1 \%{ }^{1}$ Appendiceal duplication is a very rare anomaly, with an estimated incidence of $0.004-0.009 \%$ among patients undergoing appendicectomy. ${ }^{2,3}$ Diagnosis is difficult in the preoperative period; and it is usually found incidentally during surgery. These cases, which are mostly encountered in childhood, can be found in association with the gastrointestinal other anomalies of tract, urinary system, and vertebral system. In adults, appendiceal duplication is typically an incidental finding during laparotomy foranotherindication. ${ }^{4}$

We aim to present a unique case of an adult who had appendiceal duplication with double appendicitis and review the existing literature.

\section{CASE REPORT}

A 31-year male presented to the Emergency Department with worsening abdominal pain, nausea, and vomiting. The pain started 24 hours ago in the umbilical region and subsequently migrated to the right iliac fossa. Physical examination showed the patient as sub-febrile and tachycardic. Examination of the abdomen revealed localised tenderness as well as rebound tenderness at the McBurney point. Laboratory findings showed an elevated white blood cell count $(14,500 / \mathrm{mm}-3)$ with neutrophilia.

Correspondence to: Dr. Nadir Adnan Hacım, Department of General Surgery, Bagcilar Training and Research Hospital, Istanbul, Turkey

E-mail:adnanhcm@hotmail.com

Received: January 04, 2020; Revised: April 23, 2020;

Accepted: April 23, 2020

DOI: https://doi.org/10.29271/jcpsp.2020.04.440
Computed tomography (CT) scan showed appendiceal wall thickening and mucosal contrast enhancement.

The appendix diameter was more than $8 \mathrm{~mm}$. Increased reticular density in periappendiceal mesenteric tissue and minimal fluid collection were observed, (Figure 1). With a prediagnosis of acute appendicitis, the operation was planned. The laparotomy was performed via Mc Burney's incision. The cecum was found which was surrounded by omentum. When the omentum was separated from the cecum, two appendices were observed. One of them was edematous and fragile, and was partially perforated at the apex region. The other one was normal looking. The appendices were located symmetrically on either side of the ileocaecal valve (Figure 2). Appendicectomies were performed for both of them. The postoperative period was uneventful. The patient was discharged on the second postoperative day. Histopathological examination confirmed double appendices. It was reported a rudimentary appendiceal tissue in one specimen (Figure 3) and severe acute transmural inflammation in the second appendix (Figure 4).

\section{DISCUSSION}

Intestinal duplications are extremly rare anomalies in surgical practice. They can be seen anywhere in the gastrointestinal tract from mouth to anüs. Duplication of the vermiform appendix was first described by Picoli in 1892 in a female patient with a double uterus, double colon, and double vagina. ${ }^{5}$ In 1968, Tinckler reported a malformation in a child with double penis, double bladder and a triple appendix. ${ }^{6}$ The incidence of double appendicitis was reported as $1 / 25,000$ appendicectomy specimens. ${ }^{6,7}$ On the other hand, Kijossev specified the incidence of double appendicitis as $1 / 10,956$ appendicectomy specimens. ${ }^{8}$ Until now, less than 100 patients ware described in the literature with double appendicits. Although the etiology is not known, Favara et al. found intestinal duplications with intestinal atresia. They 
hypothisised that the intestinal duplications possibly develop secondary to intrauterine vascular occlusions. ${ }^{9}$ Several classifications are used for double appendices. The Modified Cave-Wallbridge Classificiation $^{10,11}$ is used to describe the location of the appendices in relation to each other and to the cecum as well as the extent of the duplication. A complete classification system was introduced by Calota et al. ${ }^{12}$ This system classified appendicealabnormalities according tothe number and shape ofanomalies. ${ }^{12}$

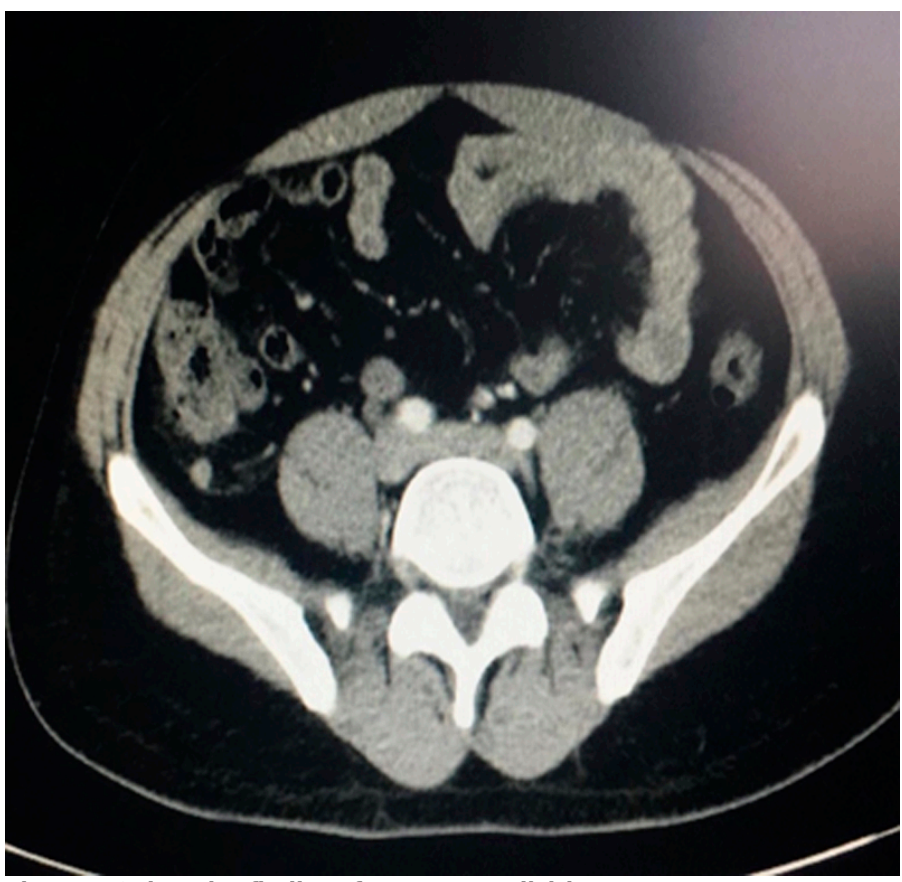

Figure 1: CTimaging finding of acute appendicitis.

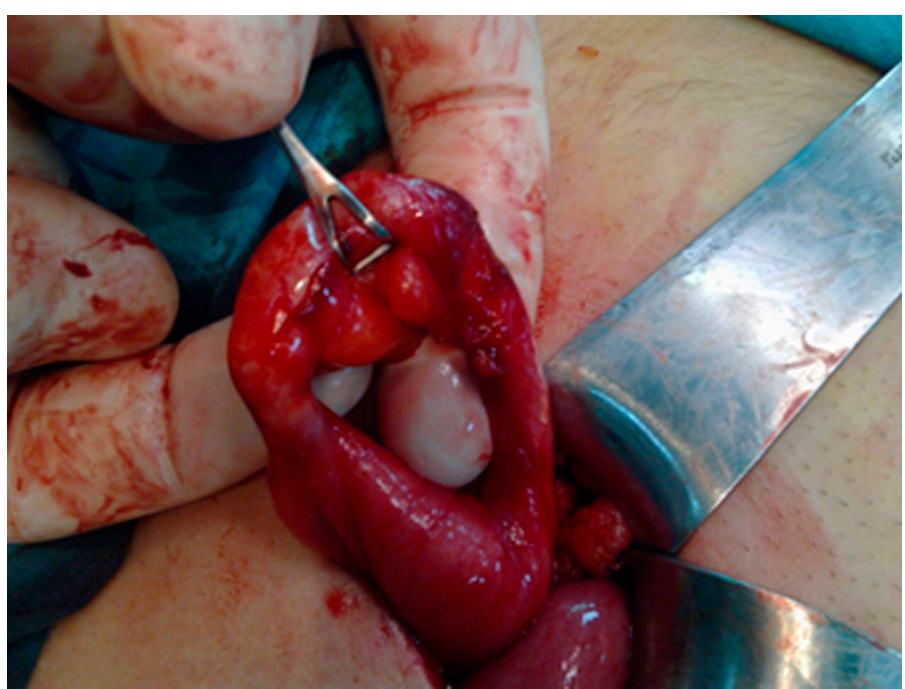

Figure 2: Intraoperative view of macroscopic appearance of double appendices.

In our case, the appendiceal duplication was like B1 according to Calota's classification. Two vermiform appendices were seen. One of them was edematous, thick-walled and semi perforated at the top region, the other was normal looking. They were adherent to each other with flimsy adhesions. They were observed as a separate continuation of the cecum. In order to prevent potential confusion, appenicectomy was performed for both appendices. The duplicate appendix may be confused with solitary cecal diverticulum. Unlike diverticulum, double appendic has Iymphoid tissue and muscular layer in its wall. This distinction can be made by histopathological methods. The pathological analysis confirmed the diagnosis of double appendices in This case.

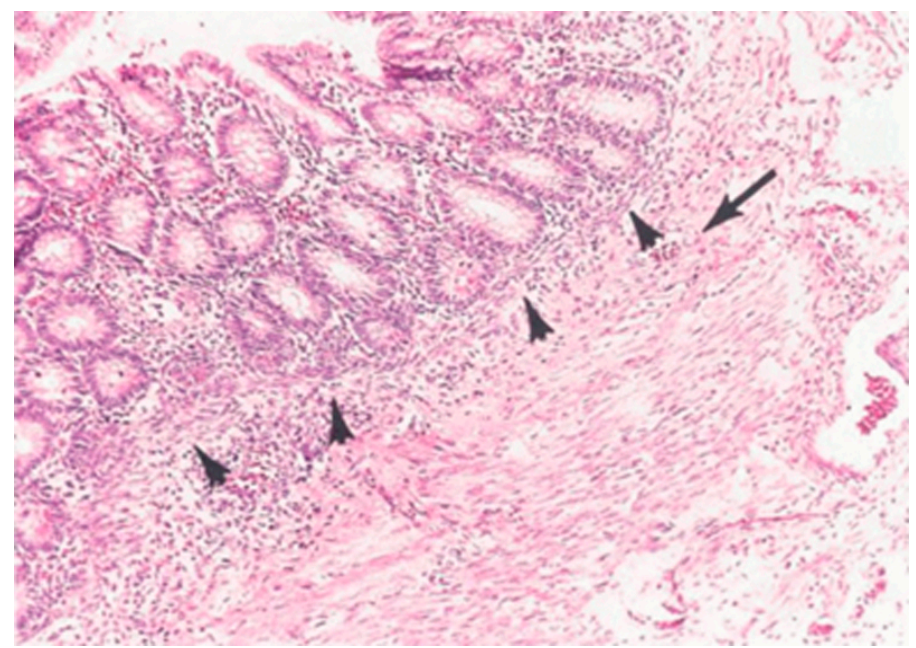

Figure 3: The histological apperance composition of the normal appering appendix. it is a rudimentary appendicial tissue. The arrows show the normal view of mucosa and submucosa.

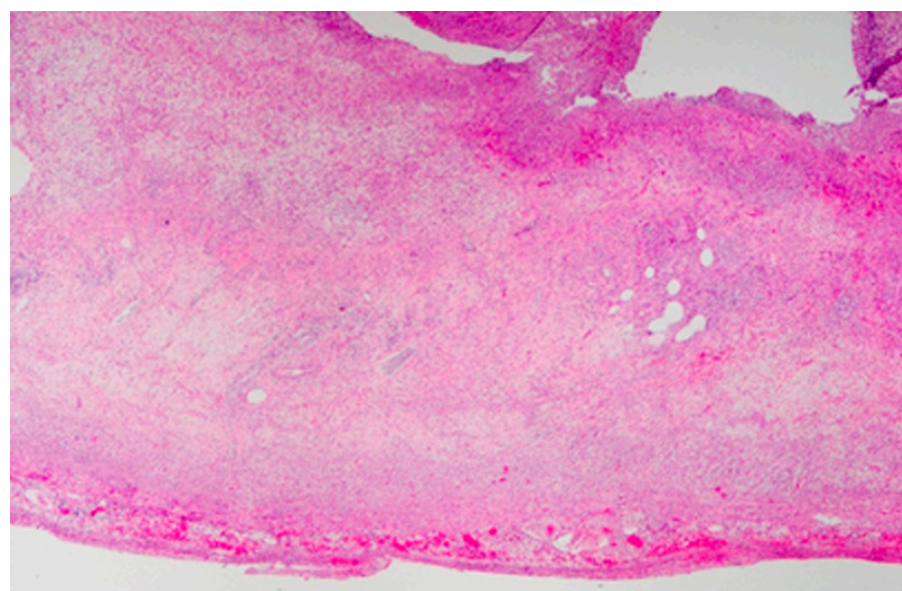

Figure 4: Histopathological apperance of the vermiform appendix with acute appendicitis.

In summary, among patients who undergo surgery with a clinical diagnosis of acute appendicitis, it is possible to observe normal appendix intraoperatively. In such cases, although it is rarely seen, surgeons should consider the possibility of double appendices. Additionally, patients with a history of appendicectomy may present again with complaints of appendicitis. Appendiceal anormalies should be considered in the differential diagnosis in suchcases.

\section{PATIENTS' CONSENT:}

Informed consent was obtained from the patient to publish the data regarding this case.

\section{CONFLICT OF INTEREST:}

Authors declared noconflict of interest.

\section{AUTHORS' CONTRIBUTION:}

AA: Conception and design, acquisition of data, drafting of manuscript, and critical revision of the manuscript.

NAH, FD: Conception, design and drafting of manuscript.

HD, ED: Acquisition of data, critical revision of the manuscriptand supervision. 


\section{REFERENCES}

1. Albayrak T, Kasim I, Kahveci R, Sencan I, Unsal S, Akca O, et al. Bir akut apandisit olgusu. Ankara Med J 2012; 12:153-5.

2. Travis JR, Weppner JL, Paugh II JC. Duplex vermiform appendix: Case report of a ruptured second appendix. J Pediatr Surg 2008; 43:1726-8.

3. Peniche González GH, Medina Vega AF, Corcuera Delgado CT, Chávez Talamantes LA, Alemán Sánchez CN, et al. First case of a vermiform appendix duplication type a volvulus a very rare cause of acute abdomen. J Pediatr Surg 2015; 3:374-6.

4. Lim KH. Duplication of the vermiform appendix in an adult patient. Ann R Coll Surg Engl 2014; 96:e16-7.

5. Bhat GA, Reshi TA, Rashid A. Duplication of vermiform appendix. Indian J Surg 2016; 78:63-4.

6. Collins DC. A study of 50,000 specimens of the human vermiform appendix. Surg Gynecol Obstet 1955; 101:437-45.

7. Tutcu Şahin S, Erhan Y, Aydede H. Double acute appendicitis in appendical duplication. Ulus Travma Acil Cerrahi Derg 2013; 19:83-5

8. Kjossev KT and Losanoff JE. Duplicated vermiform appendix. BrJ Surg 1996; 83:1259.

9. Favara BE, Franciosi RA, Akers DR. Enteric duplications thirty seven cases a vascular theory of pathogenesis. Am J Dis Child 1971; 122:501-6.

10. Cave AJE. Appendix vermiformis duplex. J Anat 1936; 70: 283-92.

11. Wallbridge PH. Double appendix. Br J Surg 1962; 50:346-7.

12. Calota F, Vasile I, Mogoantă S, Zavoi R, Paşalega M, Moraru E, Stoicea $C$, et al. Horseshoe appendix a extremely rare anomaly. Chirurgia (Bucur) 2010; 105:271-4. 